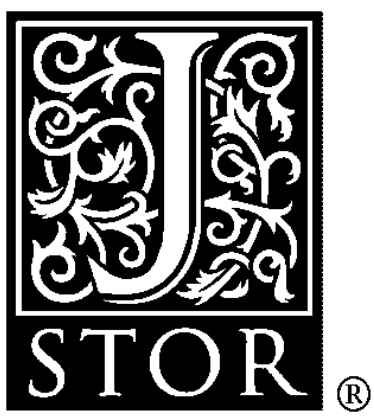

What Differences in the Cultural Backgrounds of Partners Are Detrimental for International Joint Ventures?

Author(s): Harry G. Barkema and Freek Vermeulen

Source: Journal of International Business Studies, Vol. 28, No. 4, (4th Qtr., 1997), pp. 845-864 Published by: Palgrave Macmillan Journals

Stable URL: http://www.jstor.org/stable/155497

Accessed: 16/07/2008 06:38

Your use of the JSTOR archive indicates your acceptance of JSTOR's Terms and Conditions of Use, available at http://www.jstor.org/page/info/about/policies/terms.jsp. JSTOR's Terms and Conditions of Use provides, in part, that unless you have obtained prior permission, you may not download an entire issue of a journal or multiple copies of articles, and you may use content in the JSTOR archive only for your personal, non-commercial use.

Please contact the publisher regarding any further use of this work. Publisher contact information may be obtained at http://www.jstor.org/action/showPublisher?publisherCode=pal.

Each copy of any part of a JSTOR transmission must contain the same copyright notice that appears on the screen or printed page of such transmission.

JSTOR is a not-for-profit organization founded in 1995 to build trusted digital archives for scholarship. We work with the scholarly community to preserve their work and the materials they rely upon, and to build a common research platform that promotes the discovery and use of these resources. For more information about JSTOR, please contact support@ jstor.org. 


\title{
WHAT DIFFERENCES IN THE CULTURAL BACKGROUNDS OF PARTNERS ARE DETRIMENTAL FOR INTERNATIONAL JOINT VENTURES?
}

\author{
Harry G. Barkema* and Freek Vermeulen** \\ Tilburg University
}

\begin{abstract}
An international joint venture implies that a firm has to cooperate with a partner with a different cultural background. In this study, hypotheses about which differences in national culture are most disruptive for international joint ventures were developed and tested using Hofstede's five dimensions. The study focused on how these dimensions affect the survival of international joint ventures, as well as their incidence relative to wholly owned subsidiaries. The hypotheses were tested on longitudinal data about 828 foreign entries of twenty-five Dutch multinationals in seventy-two countries between 1966 and 1994. The database, which spans almost three decades, was also used to provide new evidence on a key assumption of Hofstede's work: that cultural values are stable over time.
\end{abstract}

Entering a foreign country through an international joint venture (IJV) has several advantages, compared to entering through a wholly owned subsidiary. The IJV allows the firm to share the costs and the risks of foreign entry and to use the local partner's knowledge about the local institutional framework, local consumer tastes, and business practices [Agarwal and Ramaswami 1992; Erramilli 1991; Erramilli and Rao 1993; Gatignon and Anderson 1988; Gomes-Casseres 1989, 1990; Kogut and Singh 1988]. However, IJVs also entail unique risks, owing to the potential problems of cooperating with a partner from a different national culture [Brown, Rugman and Verbeke 1989; Harrigan 1988]. The cultural difference may create ambiguities in the relationship, which may lead to conflict and even dissolution of the venture [Barkema, Bell and Pennings 1996; Shenkar and Zeira 1992; Woodcock and Geringer 1991].

However, some differences in cultural backgrounds may be more difficult to combine than others. The main objective of this study was to determine which

\footnotetext{
* Harry G. Barkema is Professor of International Management and the Director of the Center for International Management Studies at Tilburg University, the Netherlands. His current research focuses on organizational learning, foreign entry and executive compensation.

** Freek Vermeulen is a doctoral student in organization and strategy at Tilburg University, the Netherlands. His research focuses on organizational learning and foreign direct investment.
}

The authors gratefully acknowledge the research assistance of Maarten Vankan, and the comments of Geert Hofstede.

Received: January 1997; Revised: June 1997; Accepted: June 1997. 
differences in national culture are most disruptive for IJVs. Our study builds on Hofstede's research [1980, 1991], which allows for the comparison of a large number of different cultures in a quantifiable manner (compare, for instance, Lane [1989]), addressing not only the extent to which cultures are different (compare, for instance, Ronen and Shenkar [1985]), but also in which respect they differ.

Previous studies on the influence of cultural distance often used an aggregate measure based on the four dimensions in Hofstede [1980]: power distance, uncertainty avoidance, individualism, and masculinity (see Kogut and Singh [1988]). Hofstede's more recently developed fifth dimension, long-term orientation (or Confucian dynamism) [Hofstede and Bond 1988], has received less attention, perhaps because scores were available for only twenty-three countries [Hofstede 1991]. The present study builds on Hofstede's five dimensions, including long-term orientation.

Previous empirical studies either examined whether cultural distance affects the incidence of IJVs using logit models (for instance, Kogut and Singh [1988]) or the hazard rate of IJVs using event-history analysis [Barkema et al. 1996; Barkema, Shenkar, Vermeulen, and Bell 1997; Kogut 1989]. The present study recognized that both types of analysis provide complementary information on the (potentially) disruptive impact of differences in national culture on IJVs. Hence, both were used on the same data set, which is another novel feature of this study.

Hypotheses were tested on longitudinal data on 828 foreign entries (IJVs and international wholly owned subsidiaries) of twenty-five Dutch multinationals between 1966 and 1994. The Netherlands has a long tradition of international trade and is currently the sixth largest foreign investor, after the U.S., Japan, Germany, the U.K., and France. We nevertheless expect Dutch firms to encounter problems when entering foreign cultures through IJVs.

Finally, we provide new evidence on a key assumption of Hofstede's work. Hofstede [1980, 1991] assumes that cultural values are stable over time, which implies that distances between national cultures are stable over time as well. This assumption has been challenged by various researchers (e.g., Nordström [1991]) who have argued that practices and cultural values are converging and that cultural distance may no longer be relevant. We provide new evidence on the validity of Hofstede's assumption, using data spanning almost three decades (1966-1994).

\section{HOFSTEDE'S FIVE DIMENSIONS}

Using survey research carried out between 1967 and 1978 within foreign subsidiaries of IBM, Hofstede [1980] found that national cultures differ along four dimensions: power distance, uncertainty avoidance, individualism, and masculinity. Power distance measures the degree to which people accept the 
unequal distribution of power inside organizations; uncertainty avoidance represents the degree to which people tolerate uncertainty and ambiguity in situations; individualism, as opposed to collectivism, stands for the preference of people to belong to a loosely versus a tightly knit social framework; masculinity, as opposed to femininity, represents the degree to which people prefer values of success and competition over modesty and concern for others. The original research yielded scores for forty countries, but later research [Hofstede 1983] extended this number to fifty-three countries and multicountry regions. However, the popular notion that national cultures are converging (e.g., Ohmae [1985]; O'Reilly [1991]) may cast doubt on the relevance of these dimensions in more recent times.

Concerned that the distinction in four dimensions might be the result of a questionnaire developed by a biased "western mindset," Hofstede and Bond [1988] subsequently used a questionnaire developed by Chinese scientists. They found a unique fifth dimension that they labelled "Confucian dynamism," which captures the extent to which people have a future-oriented perspective rather than a focus on the present. Hofstede [1991] later renamed this dimension "long-term orientation." However, Yeh and Lawrence [1995] have recently challenged this dimension and questioned whether it adds to the descriptive and explanatory power of the original four dimensions. They argue that this dimension reflects the same underlying cultural values as individualism and should therefore not be treated as a separate dimension.

Hofstede's initial four dimensions have often been used in research in International Business (for overviews, see Chandy and Williams [1994]; Redding [1994]; Søndergaard [1994]). Kogut and Singh [1988] were the first to combine the four dimensions into one aggregate measure of cultural distance between countries. They found that the mode of foreign direct investment is influenced by the cultural distance between the home country of the expanding firm and the host country. ${ }^{1}$ Their index of cultural distance has subsequently. been used in many other studies, including Erramilli [1991], Benito and Gripsrud [1992], Loree and Guisinger [1995], and Barkema et al. [1996]. However, Shenkar and Zeira [1992] have argued that this unidimensional index may oversimplify the rich and complex concept of cultural distance.

\section{THEORY AND HYPOTHESES}

Many scholars have addressed the difficult concept of cultural differences (for overviews, see, for instance, Adler, Doktor and Redding [1986]; Ronen and Shenkar [1985]). Culture is often defined as a system of shared values that serves two critical functions: 1) to solve problems of external adaptation and 2) to solve problems of internal integration (e.g., Schein [1985]; Schneider [1989]). External adaptation is associated with defining the objectives and the strategy of the organization, and how opportunities and threats in the environment are perceived and responded to. These perceptions and responses are influenced by 
attitudes regarding uncertainty avoidance and long-term orientation [Schneider 1989; Schneider and De Meyer 1991]. Internal integration, in contrast, bears on the firm's relationship with its employees which, in turn, is influenced by attitudes towards power distance, individualism and masculinity [Schneider 1989; Schneider and De Meyer 1991]. ${ }^{2}$

In previous studies, differences in the cultural backgrounds of the partners have generally been perceived as a threat to the survival of IJVs (see Brown, Rugman and Verbeke [1989]; Harrigan [1988]; Shenkar and Zeira [1992]; Woodcock and Geringer [1991]). Consistent with this view, various studies [Barkema et al. 1996, 1997; Li and Guisinger 1991] have found that the chances of survival of IJVs are lower when the cultural distance between the home country of the expanding firm and the host country is large. Below we will develop hypotheses regarding which differences in the cultural backgrounds of partners are particularly disruptive for IJVs. We first discuss differences along the four dimensions in Hofstede's original [1980] study. Next, we discuss differences along the more recently developed dimension long-term orientation [Hofstede and Bond 1988].

\section{IJV Survival and Hofstede's Initial Four Dimensions}

Differences in uncertainty avoidance are difficult to cope with in the case of international cooperation [Hofstede 1989]. They imply differences in how people perceive opportunities and threats in their environment, and how they act upon them [Schneider and De Meyer 1991]. Organizations in countries characterized by high uncertainty avoidance tend to respond to uncertainty in the environment by building up a system of high formalization and hierarchy [Hofstede 1980]. Employees in these countries turn to this system when confronted with events in the environment; they feel uncomfortable without such a system to hold on to. In countries where uncertainty avoidance is low, however, people feel equally uncomfortable with rigid rules and hierarchy. They feel much more attracted to flexible, ad hoc structures which leave much room for improvisation and negotiation. Uncertainty avoidance, at either pole of the dimension, reflects deep psychological needs concerning control and security [Hofstede 1989, 1991]. In sum, we expect that differences in uncertainty avoidance lead to differences in how partners perceive and respond to events in the environment of the IJV, which will likely breed disagreement and dispute between the partners, and have a detrimental impact on the IJV's chances of survival.

Power distance and individualism directly bear on issues of internal integration and influence relationships with personnel, such as the organization's choice of control forms, reward systems and so on [Hofstede 1980; Kim, Park and Suzuki 1990; Lebas and Weigenstein 1986]. However, management of personnel is usually one of the first activities to be left to the local partner to organize [Hofstede 1991; Rosten 1991; Stopford and Wells 1972]. Soeters and 
Schreuder [1988] found that U.S. multinationals did not transfer cultural values related to power distance and individualism to their Dutch subsidiaries. This suggests that tensions between the partners associated with differences along these dimensions can typically be avoided. Furthermore, Hofstede [1985] and Shenkar and Zeira [1992] suggest that having partners from both "feminine" and "masculine" cultures may even benefit the IJV. The aggressive attitude of one partner (aimed at individual achievement and performance) and the relationship orientation of the other (cf. Hofstede [1980]) may complement each other rather than collide. The above discussion suggests the following hypothesis:

H1: Differences in uncertainty avoidance between home and host country - rather than differences in power distance, individualism and masculinity - have a negative impact on IJV survival.

\section{IJV Survival and Long-Term Orientation}

Hofstede's fifth dimension, long-term orientation [Hofstede and Bond 1988; Hofstede 1991], captures the extent to which people have a pragmatic futureoriented perspective rather than a focus on the present. People in societies characterized by a long-term orientation know many truths and have a thrift for investment. In this sense, they are dynamic in their thinking. Relationships are largely ordered on the basis of status. In societies with little long-term orientation, people believe there is one absolute truth and expect quick results. This represents a more static attitude [Hofstede and Bond 1988]. ${ }^{3}$

Differences in the long-term orientation of the partners will therefore likely lead to differences in objectives and in perceived opportunities and threats in the environment of the IJV [Schneider 1988; Schneider and De Meyer 1991]. For instance, one partner may have a sense of urgency and favor quick results, while the other has a long-term view and is more oriented towards investments in financial assets and in building up a relationship with the partner. Such differences will likely breed tensions and increase the probability of untimely dissolution of the IJV.

Yeh and Lawrence [1995] recently argued that Hofstede's fifth dimension, long-term orientation, is actually strongly related to individualism. Societies in which people have a long-term orientation would tend to be collectivistic whereas those that are less long-term-oriented are more individualistic. However, we believe that the view that collectivism and long-term orientation represent the same aspect of culture is too much of a simplification. Research on Western IJVs in China - the country with the highest score on long-term orientation - suggests that different time perspectives and issues of status [Tai 1988] rather than different attitudes towards individualism lead to cultural clashes [Baird, Lyles and Wharton 1990]. It is difficult for Westerners to 
understand and handle the differences in time horizon with their Chinese partner, yet handling such differences is a prerequisite for successful cooperation [Beamish and Wang 1989; Davidson 1987]. The above discussion suggests that differences in long-term orientation cause problems in IJVs, while differences in power distance, individualism and masculinity do not necessarily lead to problems. Formally:

H2: Differences in long-term orientation between home and host country - rather than differences in power distance, individualism and masculinity - have a negative impact on IJV survival.

\section{IJV-Incidence and Cultural Differences}

Geringer and Hébert [1991] studied a range of measures of IJV performance. They found survival to be the objective measure most closely correlated to subjective measures of affiliate success. They therefore argue that in the absence of survey data, "survival" as a success measure is justifiable. Mitchell, Shaver and Yeung [1994] reviewed various studies documenting a positive relationship between the longevity of ventures and their financial performance. However, longevity is not a perfect measure of performance. Dissolution may not always imply failure and longevity does not always signal success, particularly in the case of IJVs, since these are sometimes intended to be shortlived from the start. Performance is a multidimensional phenomenon that covers financial returns, risks, knowledge transfers, and so on [Barkema et al. 1996]. Thus, studying "longevity" is useful but provides imperfect information on the impact of uncertainty avoidance and long-term orientation.

When deciding whether to enter a foreign market through an IJV or through a wholly owned subsidiary, firms will take not only expectations of future returns into account but also risks and knowledge transfers. In fact, numerous studies investigating when firms prefer IJVs over international wholly owned subsidiaries (IWOSs) have found that firms are more likely to enter through IJVs (rather than through IWOSs) when the cultural distance (measured by some aggregate index) between the home country and the host country is large [Agarwal and Ramaswami 1992; Erramilli 1991; Erramilli and Rao 1993; Gatignon and Anderson 1988; Gomes-Casseres 1989, 1990; Kogut and Singh 1988]. Firms apparently believe that it is attractive to have a local partner when they do business in a remote country. The benefits of having a partner with knowledge of local networks, consumer preferences, institutional frameworks, and so on, apparently outweigh the (potential) hazards of having to deal with a partner with a different cultural background.

However, if firms take expected costs (including the costs of cooperation) and gains into account when deciding to enter through an IJV or through an IWOS, and if differences in uncertainty avoidance and in long-term orien- 
tation between the partners are particularly disruptive for IJVs, then we expect that the inclination to set up IJVs (rather than IWOSs) is reduced more by differences along these two dimensions of national culture than by differences in masculinity, individualism and power distance. Formally:

H3: Differences in uncertainty avoidance - rather than differences in power distance, individualism and masculinity - reduce a firm's propensity to set up an IJV rather than an IWOS.

H4: Differences in long-term orientation - rather than differences in power distance, individualism and masculinity - reduce a firm's propensity to set up an IJV rather than an IWOS.

\section{Obsolescence of Hofstede's Dimensions}

A key assumption of Hofstede's work (for instance, Hofstede [1980, 1991]) is that values - the core of national culture - are stable constructs and have been present in the peoples from different nations for a long period of time (see also Schein [1985]). The research resulting in Hofstede's four dimensions took place almost three decades ago. Although these dimensions have been validated since (see Søndergaard [1994]), various researchers have endorsed the popular notion that cultures are converging (e.g., Ohmae [1985]; Levitt [1983]; O’Reilly [1991]) and have cast doubt on the explanatory power of Hofstede's dimensions in later periods (see also Adler et al. [1986]). Indeed, people from different nations are unmistakably converging in terms of clothing (Levi's jeans), food (McDonalds), beverages (Coca Cola), entertainment (MTV), and news (CNN, Business Week).

However, Hofstede's [1980, 1991] work suggests that such changes concern convergences in so-called practices, superficial appearances of culture; they do not necessarily signal a convergence in the values embedded in national cultures. Thus, Hofstede's work suggests that differences between national cultures are still relevant. The implication for the present study is that cultural differences between partners are still disruptive for IJVs. We therefore expect that cultural differences had both a negative impact on the survival of IJVs during the beginning of our period under consideration 1966-1994 (which coincides with the period when Hofstede did his original research) and during later periods. Formally:

H5. The impact of cultural distance on IJV survival - measured by Hofstede's dimensions - has not disappeared over time.

\section{METHODOLOGY}

\section{Sample}

The study used data on the foreign expansions of twenty-five large nonfinancial Dutch firms. These firms represent all non-financial firms listed on 
the Amsterdam Stock Exchange in 1993, except the four largest firms (Royal Dutch, Unilever, Philips, and Akzo) because they differed considerably in terms of international experience, size and scope. In fact, Royal Dutch and Unilever formally have their headquarters both in the Netherlands and in the U.K. The database contained all foreign expansions reported in the annual reports of these firms between 1966 and 1994. In case of doubt, representatives were contacted by telephone and fax to verify information. The total number of international ventures was 828: 228 IJVs and 600 IWOSs. The entries covered seventy-two different countries.

\section{Variables}

Longevity. Venture survival was measured by its longevity: the number of years the venture persisted, as registered in the firm's annual reports (cf. Barkema et al. [1996]; Li [1995]; Mitchell et al. [1994]; Pennings, Barkema and Douma [1994]). Forty-nine percent of the IJVs were terminated before the end of the period under consideration (i.e., was left-censored in 1994). ${ }^{4}$

Cultural Distance. The cultural distance between the host country and the home country of the expanding firm (the Netherlands) was measured by Hofstede's cultural dimensions. Data on the initial four dimensions were obtained from Hofstede [1980, 1991]. If unavailable, scores were obtained through personal communication with the author. Scores on the fifth dimension, long-term orientation, were only available for eighteen of the seventythree countries (including the Netherlands). Therefore, we used the following proxy (cf. Read [1993]): a country's "marginal propensity to save." This proxy is a macroeconomic variable measuring a country's marginal propensity to save rather than consume incremental, disposable national income. It is defined as:

$$
\delta(S / n) / \delta(C / n+S / n),
$$

where $\delta(S / n)$ is the absolute change in real per capita gross domestic saving from 1970-1990, and $\delta(C / n)$ is the absolute change in real per capita private consumption from 1970-1990. Data were obtained from Read [1993]. This variable is theoretically appealing since it relates to the element of thrift in long-term orientation. Read reports a correlation between long-term orientation and his proxy of .584 . His proxy outperformed two other proxies in a test of construct validity.

For reasons of comparability, scores on all five dimensions were standardized for the set of seventy-three countries. Cultural distance was computed in two different ways. First, following Kogut and Singh [1988], as the arithmetic average of the squared deviations of each country from the ranking of the Netherlands. ${ }^{5}$ Second, in conformity with Euclidean distance, as the squareroot of the squared deviations of each country from the ranking of the Netherlands. ${ }^{6}$ Algebraically: 


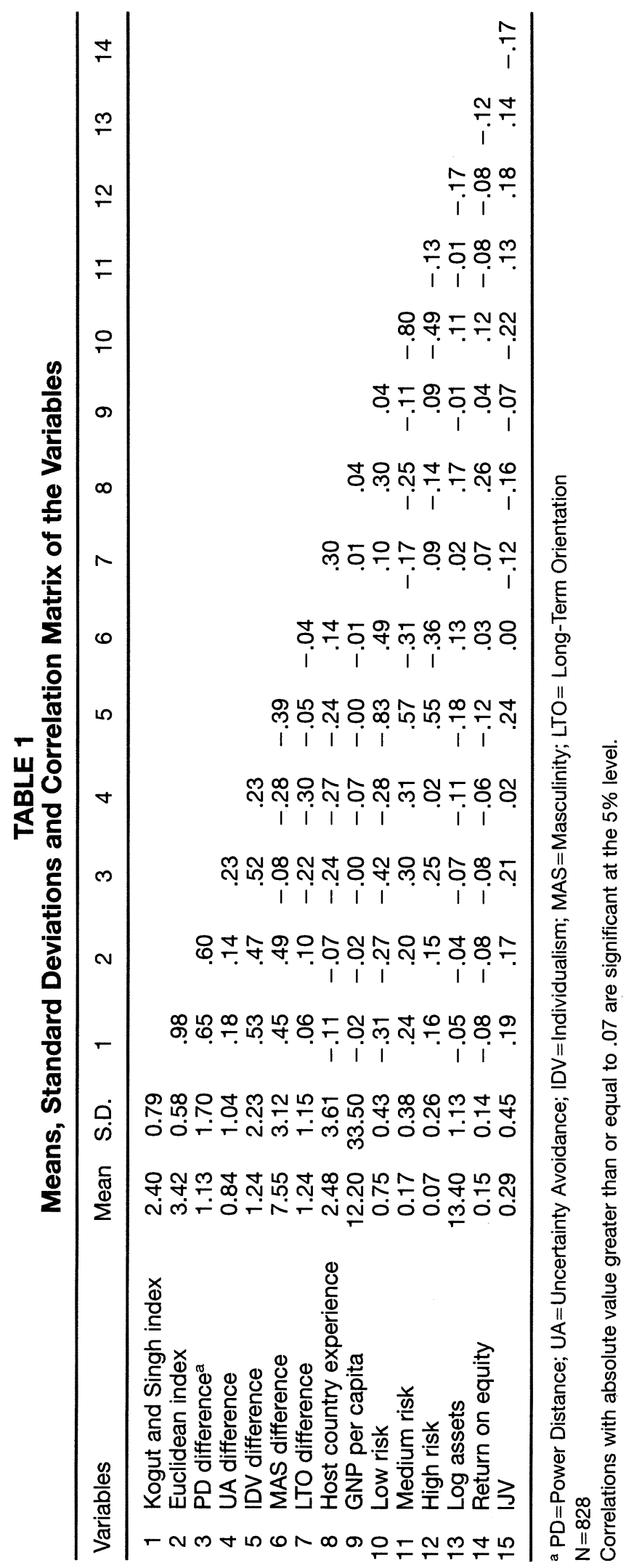




$$
\begin{array}{ll}
\text { Kogut and Singh index: } & C D_{j}=\Sigma_{i=1,2,3,4,5}\left(\left(I_{i j}-I_{i n}\right)^{2} / V_{i}\right) / 5, \\
\text { Euclidean index: } & C D_{j}=\sqrt{ } \Sigma_{i=1,2,3,4,5}\left(\left(I_{i j}-I_{i n}\right)^{2} / V_{i}\right),
\end{array}
$$

where,

$$
\begin{aligned}
C D_{j} & =\text { cultural distance of the } j^{\text {th }} \text { country from the Netherlands; } \\
I_{i j} & =\text { index for the } i^{\text {th }} \text { cultural dimension and } j^{\text {th }} \text { country; } \\
n & =\text { the Netherlands; } \\
V_{i} & =\text { the variance of the index of the } i^{\text {th }} \text { dimension. }
\end{aligned}
$$

Control Variables. A firm's experience in a host country influences the survival of its ventures [Barkema et al. 1996] and its preference for IJVs over IWOSs [Gomes-Casseres 1989, 1990; Hennart 1991]. Therefore we controlled for local experience, proxied by the number of previous entries of the firm in the host country (cf. Kogut and Singh [1988]). We also controlled for differences in Gross National Product per capita since this may correlate with national culture [Hofstede 1980]. The three clusters of country risk developed by Goodnow and Hansz [1972] were used to control for country risk (cf. Gatignon and Anderson [1988]). ${ }^{7}$ Finally, because a firm's resources may influence a venture's ownership structure and survival, we controlled for firm profitability and size, using return on equity and the log of the firm's assets, respectively. Summary statistics are presented in Table 1.

\section{Analysis}

The hypotheses regarding venture survival were tested by event history analysis. Cox's semiparametric model was used because this model does not require us to specify the (unknown) baseline hazard function. Since the time scale of survival time is discrete and ties might be extensive, we used the discrete logistic model. A positive coefficient indicates that the variable enhanced the survival of the ventures.

Hypotheses concerning the incidence of IJVs versus IWOSs were tested using conventional binomial logit models. The dependent variable was a dummy capturing whether the venture was an IJV or an IWOS.

\section{RESULTS}

\section{Testing the Hypotheses}

Previous studies have found that cultural distance negatively affects the survival of IJVs but that, nevertheless, the greater the distance, the more likely the incidence of IJVs (relative to IWOSs). We first determined whether these regularities also exised in our data. Models 1 and 2 in Table 2 display the results from the event history analyses. Model 1 uses Kogut and Singh's index of cultural distance based on Hofstede's initial four dimensions, and Model 2 uses his five dimensions. The results show that cultural distance - measured at 
TABLE 2

Survival and Incidence: IJVs versus IWOSs

\begin{tabular}{lccccc}
\hline & \multicolumn{2}{c}{ Event History IJVs } & & \multicolumn{2}{c}{ Logit IJV versus IWOS } \\
\cline { 2 - 3 } \cline { 6 - 7 } Variables & Model 1 & Model 2 & & Model 3 & Model 4 \\
\hline Intercept & & & $-6.526^{\star \star \star}$ & $-6.361^{\star \star \star}$ \\
& & & & $(5.97)$ & $(5.83)$ \\
Cultural distance 4b & $-0.133 \dagger$ & & & $0.365^{\star \star \star}$ & \\
& $(1.46)$ & & & $(4.35)$ & \\
Cultural distance 5 & & $-0.224^{\star}$ & & & $0.388^{\star \star \star}$ \\
& & $(1.90)$ & & & $(3.70)$ \\
Host country experience & $0.087^{\star}$ & $0.090^{\star}$ & & $-0.080^{\star \star}$ & $-0.084^{\star \star}$ \\
GNP per capita & $(2.02)$ & $(2.09)$ & & $(2.67)$ & $(2.80)$ \\
& -0.018 & -0.019 & & -0.040 & $-0.045 \dagger$ \\
Medium risk & $(0.51)$ & $(0.56)$ & & $(1.54)$ & $(1.73)$ \\
& -0.408 & -0.396 & & 0.086 & 0.093 \\
High risk & $(1.05)$ & $(1.03)$ & & $(0.29)$ & $(0.31)$ \\
& -0.360 & -0.333 & & $1.059^{\star \star}$ & $0.985^{\star}$ \\
Log assets & $(0.80)$ & $(0.74)$ & & $(2.68)$ & $(2.48)$ \\
& $-0.160 \dagger$ & $-0.157 \dagger$ & & $0.394^{\star \star \star}$ & $0.391^{\star \star \star}$ \\
Return on equity & $(1.80)$ & $(1.76)$ & & $(5.12)$ & $(5.14)$ \\
& -1.523 & -1.481 & & $-1.616^{\star}$ & $-1.594^{\star}$ \\
Number of observations & $(1.38)$ & $(1.35)$ & & $(2.28)$ & $(2.25)$ \\
Percentage censored & & 228 & & & 828 \\
Log likelihood & & 51.32 & & & \\
Percentage correct & -370.4 & -369.6 & -438.0 & -440.7 \\
\hline
\end{tabular}

a $\mid J V=1$

${ }^{b}$ Kogut \& Singh index

$T$-statistics are in parentheses.

$\dagger p<0.10 ;{ }^{*} p<0.05 ;{ }^{\star \star} p<0.01 ;{ }^{\star \star \star} p<0.001$ (one-tailed if hypothesized, two-tailed if not)

an aggregate level - does indeed hurt IJV survival, in particular if all five dimensions are included in the cultural distance index. ${ }^{8}$ Models 3 and 4 are logit models. The results show that the incidence of IJVs increases with cultural distance. The effect is highly significant. In sum, the regularities found in previous studies [Agarwal and Ramaswami 1992; Barkema et al. 1996, 1997; Erramilli 1991; Erramilli and Rao 1993; Gatignon and Anderson 1988; Gomes-Casseres 1989, 1990; Kogut and Singh 1988; Li and Guisinger 1991] also apply to our data. ${ }^{9}$

$\mathrm{H}_{1}$ and $\mathrm{H}_{2}$ imply that the chances of survival of IJVs decrease in uncertainty avoidance and long-term orientation rather than in the other three dimensions of cultural distance (individualism, power distance, masculinity). The event history analysis results are presented in Model 1 in Table 3. The effects of uncertainty avoidance and long-term orientation are negative and significant, while the effects of power distance and individualism are not. Differences in masculinity have a significant, negative impact on the survival of IJVs but the effect is smaller than the effects of uncertainty avoidance and long-term 
TABLE 3

Separate Cultural Dimensions

\begin{tabular}{lcc}
\hline & $\begin{array}{c}\text { Event History } \\
\text { IJVs } \\
\text { Model 1 }\end{array}$ & $\begin{array}{c}\text { Logit } \\
\text { IJV vs IWOS } \\
\text { Model } 3\end{array}$ \\
\hline Variables & & $-6.140^{\star \star \star}$ \\
Intercept & 0.005 & $(5.54)$ \\
Power Distance difference & $(0.07)$ & $0.098^{\star}$ \\
Uncertainty Avoidance difference & $-0.255^{\star}$ & $(1.78)$ \\
& $(2.01)$ & $-0.129 \dagger$ \\
Individualism difference & 0.068 & $(1.40)$ \\
& $(0.91)$ & $0.137^{\star}$ \\
Masculinity difference & $-0.110^{\star}$ & $(1.99)$ \\
& $(2.34)$ & $0.074^{\star}$ \\
Long-Term Orientation difference & $-0.310^{\star \star}$ & $(2.31)$ \\
Host country experience & $(2.61)$ & $-0.189^{\star}$ \\
& $0.086 \dagger$ & $(2.30)$ \\
GNP per capita & $(1.87)$ & $-0.086^{\star \star}$ \\
Medium risk & -0.000 & $(2.77)$ \\
& $(0.00)$ & -0.024 \\
High risk & $-1.078 \dagger$ & $(0.89)$ \\
& $(1.82)$ & 0.079 \\
Log assets & -1.118 & $(0.18)$ \\
Return on equity & $(1.53)$ & $1.015 \dagger$ \\
& -0.143 & $(1.77)$ \\
Number of observations & $(1.59)$ & $0.390^{\star \star \star}$ \\
Percentage censored & -1.715 & $(5.00)$ \\
Log likelihood & $(1.52)$ & $-1.644^{\star}$ \\
Percentage correct & 228 & $(2.31)$ \\
\hline
\end{tabular}

a $\mid J V=1$

$T$-statistics are in parentheses.

$\dagger p<0.10 ;{ }^{*} p<0.05 ;{ }^{* \star} p<0.01 ;{ }^{\star \star \star} p<0.001$ (one-tailed if hypothesized, two-tailed if not)

orientation. ${ }^{10}$ Additional testing of the dimensions against each other showed that the effect of long-term orientation is significantly larger than the effects of power distance $(p<0.01)$, individualism $(p<0.01)$ and masculinity $(p<0.05)$. The effect of uncertainty avoidance is significantly larger than the effects of power distance $(p<0.05)$ and of individualism $(p<0.05)$, while the difference with the effect of masculinity approaches significance $(p<0.12)$. Thus, the results generally support $\mathrm{H}_{1}$ and $\mathrm{H}_{2}$.

$\mathrm{H}_{3}$ and $\mathrm{H}_{4}$ predict that differences in uncertainty avoidance and in long-term orientation, rather than differences along the other three dimensions, reduce a firm's inclination to establish IJVs in a foreign country. Model 2 presents logit model results. The effects of uncertainty avoidance and long-term orientation are negative and significant, which suggests that firms are reluctant to establish 
IJVs when differences in uncertainty avoidance and long-term orientation are large. In contrast, differences along the other three dimensions lead to a preference of IJV over IWOS. Additional tests show, not surprisingly, that uncertainty avoidance and long-term orientation have a significantly more negative impact on IJV incidence than power distance $(p<0.05, p<0.001)$, individualism $(p<0.05, p<0.01)$, and masculinity $(p<0.05, p<0.001)$. These results strongly corroborate $\mathrm{H}_{3}$ and $\mathrm{H}_{4}$.

Finally, $\mathrm{H}_{5}$ predicts that the impact of cultural distance on IJV survival has not disappeared over time. Table 4 contains estimation results with the effect of cultural distance broken up in smaller time spans (using dummies). ${ }^{11}$ In the first two models, cultural distance is measured using Hofstede's dimensions in the Kogut and Singh index. In the third and fourth model, those dimensions are combined in the Euclidean index. Models 1 and 3 break up the 1966-1994 period into two parts: 1966-1980 and 1981-1994. The results do not show a decrease in the effect of cultural distance over time (i.e., across the two

TABLE 4 Cultural Distance in Course of Time

\begin{tabular}{|c|c|c|c|c|}
\hline \multirow[b]{2}{*}{ Variables } & \multicolumn{2}{|c|}{ Kogut \& Singh Index } & \multicolumn{2}{|c|}{ Euclidean Index } \\
\hline & Model 1 & Model 2 & Model 3 & Model 4 \\
\hline Cultural distance 1966-1980 & $\begin{array}{c}-0.212^{\star} \\
(1.77)\end{array}$ & & $\begin{array}{c}-0.418^{\star \star} \\
(2.34)\end{array}$ & \\
\hline Cultural distance 1980-1994 & $\begin{array}{c}-0.270^{\star} \\
(1.81)\end{array}$ & & $\begin{array}{c}-0.463^{\star \star} \\
(2.44)\end{array}$ & \\
\hline Cultural distance 1966-1973 & & $\begin{array}{c}-0.230^{\star} \\
(1.72)\end{array}$ & & $\begin{array}{c}-0.461^{\star \star} \\
(2.41)\end{array}$ \\
\hline Cultural distance 1973-1980 & & $\begin{array}{c}-0.193 \dagger \\
(1.54)\end{array}$ & & $\begin{array}{c}-0.405^{\star} \\
(2.24)\end{array}$ \\
\hline Cultural distance 1980-1987 & & $\begin{array}{c}-0.264^{\star} \\
(1.76)\end{array}$ & & $\begin{array}{c}-0.475^{\star \star} \\
(2.46)\end{array}$ \\
\hline Cultural distance 1987-1994 & & $\begin{array}{c}-0.303 \dagger \\
(1.52)\end{array}$ & & $\begin{array}{c}-0.506^{\star \star} \\
(2.32)\end{array}$ \\
\hline Host country experience & $\begin{array}{l}0.095^{\star} \\
(2.16)\end{array}$ & $\begin{array}{l}0.095^{\star} \\
(2.11)\end{array}$ & $\begin{array}{l}0.098^{\star} \\
(2.23)\end{array}$ & $\begin{array}{l}0.098^{*} \\
(2.13)\end{array}$ \\
\hline GNP per capita & $\begin{array}{c}-0.017 \\
(0.50)\end{array}$ & $\begin{array}{c}-0.017 \\
(0.49)\end{array}$ & $\begin{array}{c}-0.020 \\
(0.59)\end{array}$ & $\begin{array}{c}-0.020 \\
(0.57)\end{array}$ \\
\hline Medium risk & $\begin{array}{c}-0.384 \\
(1.00)\end{array}$ & $\begin{array}{c}-0.376 \\
(0.96)\end{array}$ & $\begin{array}{c}-0.394 \\
(1.03)\end{array}$ & $\begin{array}{c}-0.387 \\
(0.99)\end{array}$ \\
\hline High risk & $\begin{array}{c}-0.324 \\
(0.72)\end{array}$ & $\begin{array}{c}-0.322 \\
(0.71)\end{array}$ & $\begin{array}{c}-0.335 \\
(0.74)\end{array}$ & $\begin{array}{c}-0.329 \\
(0.72)\end{array}$ \\
\hline Log assets & $\begin{array}{c}-0.138 \\
(1.44)\end{array}$ & $\begin{array}{c}-0.134 \\
(1.38)\end{array}$ & $\begin{array}{c}-0.137 \\
(1.43)\end{array}$ & $\begin{array}{c}-0.131 \\
(1.34)\end{array}$ \\
\hline Return on equity & $\begin{array}{c}-1.292 \\
(1.11)\end{array}$ & $\begin{array}{c}-1.218 \\
(1.02)\end{array}$ & $\begin{array}{c}-1.237 \\
(1.05)\end{array}$ & $\begin{array}{c}-1.095 \\
(0.91)\end{array}$ \\
\hline Log likelihood & -369.5 & -369.3 & -368.4 & -367.9 \\
\hline
\end{tabular}


periods). Models 2 and 4 contain more fine-grained analyses using four time periods. Again, there is no indication that the effect of cultural distance has decreased over time. Formal tests of whether one of the cultural distance variables differed from a cultural distance variable in any other period could not be confirmed at any reasonable level of significance. Finally, to avoid breaking up the observations into different time periods, we defined a continuous variable "time" $(1966=1,1994=29)$ and an interaction between this variable and the cultural distance index. The interaction was highly insignificant in all models, as was the interaction between cultural distance and the logarithm of time. The evidence is consistent with $\mathrm{H}_{5}$.

\section{Sensitivity Analysis}

Political Context. The choice of entry mode, as well as the survival chances of IJVs, might be influenced by factors in the political context of the host country other than those captured by our variables risk and GNP per capita (e.g., Stopford and Wells [1972]). Therefore we reestimated our models expanded with two additional variables which operationalized political context: a timevariant political rights indicator, based on publications in Freedom at Large and Freedom Review (see Read [1993]), and a time-variant measure of openness to international trade, using the relative size of a country's imports and exports (cf. Read [1993]). The first variable did not have an effect in any of the models. In the logit models, openness to international trade indicated a significant preference for IWOS over IJV $(p<0.05)$. However, the effects of the cultural distance variables (capturing our hypotheses) in the event history analyses and in the logit models did not decrease when the political context variables were included in the models.

Firm-Specific Effects. Since all our observations stem from twenty-five firms, the results might be affected by firm-specific effects. Therefore, we reestimated all our models with firm dummies. As might be expected, control variables at the firm level - host country experience, log assets and return on equity - were sometimes affected by the inclusion of the firm dummies. The inclusion of firm dummies did not decrease the support for our hypotheses.

Host Country Experience. We defined the control variable host country experience as the number of previous entries of the firm in the host country. However, the time the firm has spent in the country might be of influence as well. Therefore, we defined an alternative measure of local experience: the number of years the firm had been present in the country (cf. Hennart [1991]). Models estimated with this variable obtained results highly similar to the ones reported above. Finally, models estimated with host country experience measured as the number of previous entries weighted with the ventures' longevity (which captures both the number of trials in the particular country and the learning period associated with these trials) obtained equally supportive results. ${ }^{12}$ 


\section{DISCUSSION AND CONCLUSIONS}

Differences in the cultural backgrounds of partners cause problems in IJVs [Barkema et al. 1996; Shenkar and Zeira 1992; Woodcock and Geringer 1991] but, as this study shows, some differences are more disruptive than others. Differences in uncertainty avoidance and long-term orientation (cf. Hofstede [1980, 1991]), in particular, cause problems. These differences have a negative impact on IJV survival and decrease the likelihood that firms enter a foreign country through an IJV rather than through an IWOS. Apparently, these differences, which translate into differences in how IJV partners perceive and adapt to opportunities and threats in their environment [Schneider 1991; Schneider and De Meyer 1991], are more difficult to resolve than differences along the other three dimensions. Perhaps cultural differences regarding power distance, individualism and masculinity are more easily resolved because they are mainly reflected in different attitudes towards the management of personnel - something firms can make explicit agreements about before entering the partnership.

A "stylized fact" in the literature (replicated in this study) is that IJV incidence correlates positively with an aggregate index of cultural distance [Agarwal and Ramaswami 1992; Erramilli 1991; Erramilli and Rao 1993; Gatignon and Anderson 1988; Gomes-Casseres 1989, 1990; Kogut and Singh 1988]. However, our more fine-grained analysis at the level of the five individual dimensions shows that IJV incidence correlates negatively with differences in uncertainty avoidance and in long-term orientation. Apparently, managers are aware of the problems caused by differences along these dimensions (which, as our study shows, may lead to early dissolution of IJVs) when evaluating whether or not to expand alone or with a local partner; such differences reduce their propensity to enter through IJVs rather than through IWOSs. These more subtle patterns are confounded when influences of aggregate measures of cultural distance are analyzed.

Our results support a key assumption of Hofstede's [1980, 1991] work: that values are stable over time. Various studies have recently cast doubt on the validity of this assumption (e.g., Ohmae [1985]; Levitt [1983]; O’Reilly [1991]). Indeed, practices such as clothing (Levi's jeans), food consumption (Coca Cola, McDonalds), news (CNN, Business Week), and entertainment (MTV), are unmistakably converging. However, our results do not show a decrease in the effect of cultural distance over the last three decades (1966-1994), which suggests that differences in values embedded in national cultures continue to lead to untimely dissolutions of IJVs and to influence the strategic choice of whether to enter a foreign country alone (i.e., an IWOS) or with a partner (an IJV).

Our results also indicate that, at least in the context of IJVs, Hofstede's fifth dimension "long-term orientation" and its proxy "marginal propensity to 
save" (cf. Read [1993]) are important additions to his original research. The effect of long-term orientation was stronger than that of any of the other dimensions of culture in all our models. The addition of long-term orientation to the other four cultural dimensions led to a significant drop $(p<0.05)$ in the log likelihood of these models (results not shown here). Thus, we encourage the use of this dimension in future research.

Our study has various limitations. The most prominent one is that we rely solely on Hofstede's [1980; 1991] dimensions to measure cultural differences. These dimensions have often been used (see Chandy and Williams [1994]; Hickson [1996]), but Hofstede's work has also been criticized (Roberts and Boyacigiller [1984]; Triandis [1982]). For instance, using countries as a unit of analysis to address cultural differences is an obvious simplification because cultural differences do not strictly follow country borders. Furthermore, a rich and complex concept such as cultural diversity cannot fully be captured by research using surveys [Lane 1989]. Such criticism also applies to our research. Future studies using other measures of cultural differences will add to the present study.

\section{NOTES}

1. Kogut and Singh [1988] also found that the mode of foreign entry is influenced by the level of uncertainty avoidance of the home country of the expanding firm.

2. Power distance refers to the relationship between management and subordinates, individualism is the relationship of the individual to the group. These are purely issues of how people relate to one another within the organization, irrespective of the environment. These two dimensions therefore concern internal integration. Masculinity is reflected in the emphasis the organization places on employee achievement versus social relationships and welfare. This generally involves internal integration as well because it determines the relationship between the organization and the employee.

3. The research [Hofstede and Bond 1988] yielded scores on this dimension for 23 countries. Countries in the Far East scored fairly high on long-term orientation, although scores still differed considerably, from 75 for South Korea to 112 for China. The Netherlands scored highest in the Western world with 44, and Great Britain scored lowest with 25. The African countries were among the lowest on long-term orientation.

4. Executives of a subset of five firms were asked to rate the success of international joint ventures in our dataset $(\mathrm{N}=31)$ on a seven-point Likert scale. Like Geringer and Hébert [1991], we calculated the Spearman correlation between the longevity of these international joint ventures and their success as perceived by the managers. The correlation coefficient was $0.55(p<0.001)$, comparable to the coefficient found by Geringer and Hébert $(0.46)$.

5. Scores on all five dimensions were available for eighteen countries. Yeh and Lawrence [1995] report that, with Pakistan excluded from the set, the correlation between long-term orientation and individualism is -.70 . We found an even higher correlation (for the same 18 countries) when long-term orientation was replaced by marginal propensity to save: -.84 . However, the correlation between marginal propensity to save and individualism is only -.16 for our total set of seventy-three countries. Thus, our data do not support the view that longterm orientation and individualism are highly correlated.

6. Thus, consistent with the notion of Euclidean distance, our Euclidean index computes the distance between two points in multidimensional space as the square root of the sum of the squares of the distances along the individual dimensions. 
7. Because Goodnow and Hansz's allocation of countries over the three categories is based on the pre-1970 setting, we compared their classification with more recent data on country risk published by Euromoney since 1982. For all countries, we computed the average Euromoney score. For a few countries, the original classification by Goodnow and Hansz did not seem representative for the period we considerated (1966-1994), and was therefore adjusted.

8. For reasons of comparison, we also estimated the event history models on IWOSs. No significant effects of cultural distance were found for these ventures. This suggests that the detrimental effect of cultural differences concerns intercultural cooperation (i.e., IJVs) rather than mere presence in a strange cultural environment (as is also the case in IWOSs).

9. The results in Table 3 are based on the Kogut and Singh [1988] index of cultural distance. Models using the Euclidean index led to slightly more significant effects in the case of event history models, and slightly less significant effects (but still $p<0.01$ ) in the case of logit models.

10. Again for reasons of comparison, we also calculated event history analysis results for IWOSs. No significant effects were found for uncertainty avoidance and only a weakly significant $(p<0.10)$ effect was found for long-term orientation. Thus, IWOSs appear to be less sensitive than IJVs to differences in uncertainty avoidance and long-term orientation between the home country of the expanding firm and the host country.

11. For example, we defined two dummies: First, one dummy valued 1 if the venture was established between 1966 and 1980, otherwise it was 0. Second, one dummy valued 1 if the venture was established between 1980 and 1994, otherwise it was 0 . Next we defined interactions between the cultural distance index and the dummy variables, and used those as explanatory variables in the event history model. For instance, cultural distance 1980-1994 measured the partial correlation between the cultural distance index and the survival of ventures established after 1980. If national cultures have converged, we would not expect an explanatory variable based on Hofstede's dimensions to explain recent IJV survival.

12. Furthermore, we split up host country experience into experience with IWOSs and experience with IJVs. Previous IWOSs increased a firm's propensity to set up IWOSs $(-0.0125, p<0.0001)$, and previous IJVs increased a firm's propensity to set up new IJVs $(0.0135, p<0.01)$. This suggests that experience with partner firms in a host country teaches the company how to cooperate with firms from that particular culture (compare Barkema et al. [1997]). The more fine-grained modelling of host country experience did not influence the support for our hypotheses.

\section{REFERENCES}

Adler, Nancy J., Robert Doktor \& S. Gordon Redding. 1986. From the Atlantic to the Pacific century: Cross-cultural management reviewed. Journal of Management, 12:295-318.

Agarwal, Sanjeev \& Sridhar N. Ramaswami. 1992. Choice of organizational form in foreign markets: A transaction cost perspective. Paper presented at the 1992 AIB Annual Meeting in Brussels.

Baird, Inga S., Marjorie A. Lyles \& Robert Wharton. 1990. Attitudinal differences between American and Chinese managers regarding joint venture management. Management International Review, 30(Special Issue):53-68.

Barkema, Harry G., John H.J. Bell \& Johannes M. Pennings. 1996. Foreign entry, cultural barriers, and learning. Strategic Management Journal, 17:151-66.

Barkema, Harry G., Oded Shenkar, Freek Vermeulen \& John H.J. Bell. 1997. Working abroad, working with others: How firms learn to operate international joint ventures. Academy of Management Journal, 40:426-42.

Beamish, Paul W. \& Hui Y. Wang. 1989. Investing in China via joint ventures. Management International Review, 29:57-64. 
Benito, Gabriel R.G. \& Geir Gripsrud. 1992. The expansion of foreign direct investments: Discrete rational location choices or a cultural learning process? Journal of International Business Studies, 23:461-76.

Brown, Lee T., Alan M. Rugman \& Alain Verbeke. 1989. Japanese joint ventures with western multinationals: Synthesising the economic and cultural explanations of failure. Asia Pacific Journal of Management, 6:225-42.

Chandy, P.R. \& Thomas G.E. Williams. 1994. The impact of journals and authors on international business research: A citational analysis of JIBS articles. Journal of International Business Studies, 25(4):715-28.

Davidson, William H. 1987. Creating and managing joint ventures in China. California Management Review, 29:77-94.

Erramilli, M. Krishna. 1991. The experience factor in foreign market entry behavior of service firms. Journal of International Business Studies, 22(3): 479-501.

— \& C.P. Rao. 1993. Service firms' international entry mode choice: A modified transactioncost analysis approach. Journal of Marketing, 57:19-38.

Gatignon, Hubert \& Erin Anderson. 1988. The multinational corporation's degree of control over foreign subsidiaries: An empirical test of a transaction cost explanation. Journal of Law, Economics, and Organization, 4:305-36.

Geringer, J. Michael \& Louis Hébert. 1991. Measuring performance of international joint ventures. Journal of International Business Studies, 22(2):249-63.

Gomes-Casseres, Benjamin. 1989. Ownership structures of foreign subsidiaries. Journal of Economic Behavior and Organization, 11:1-25.

- 1990. Firm ownership preferences and host government restrictions: An integrated approach. Journal of International Business Studies, 21(1):1-22.

Goodnow, James D. \& James E. Hansz. 1972. Environmental determinants of overseas market entry strategies. Journal of International Business Studies, 3:33-50.

Harrigan, Kathryn R. 1988. Strategic alliances and partner asymmetries. In F.J. Contractor \& P. Lorange, editors. Cooperative strategies in international business, 205-26. Lexington, Mass.: Lexington Books.

Hennart, Jean-François, 1991. The transaction costs theory of joint ventures: An empirical study of Japanese subsidiaries in the United States. Management Science, 37:483-497.

Hickson, David J. 1996. The ASQ years then and now through the eyes of a Euro-Brit. Administrative Science Quarterly, 41:217-28.

Hofstede, Geert. 1980. Culture's consequences. International differences in work-related values. Beverly Hills, Calif.: Sage.

- 1983. Dimensions of national cultures in fifty countries and three regions. In J.B. Deregowkski, S. Dziurawiec \& R.C. Annis, editors, Cross-cultural contributions to psychology, 389-407. Lisse, The Netherlands: Wets and Zeitlinger.

- 1985. The interaction between national and organizational value systems. Journal of Management Studies, 22:347-57.

—. 1989. Organising for cultural diversity. European Management Journal, 7:390-97.

- 1991. Cultures and organizations: Software of the mind. Berkshire, U.K.: McGraw-Hill.

— \& Michael H. Bond. 1988. The Confucius connection: From cultural roots to economic growth. Organizational Dynamics, 16:5-21. 
Kim, Ken I., Hun-Joon Park \& Nori Suzuki. 1990. Reward allocations in the United States, Japan, and Korea: A comparison of individualistic and collectivistic cultures. Academy of Management Journal, 33:188-98.

Kogut, Bruce. 1989. The stability of joint ventures: Reciprocity and competitive rivalry. Journal of Industrial Economics, 38:183-98.

_ \& Harbir Singh. 1988. The effect of national culture on the choice of entry mode. Journal of International Business Studies, 19(3):411-32.

Lane, Christel. 1989. Management and labour in Europe. The industrial enterprise in Germany, Britain and France. Aldershot, U.K.: Edward Elgar.

Lebas, Michel \& Jane Weigenstein. 1986. Management control: The roles of rules, markets and culture. Journal of Management Studies, 23:259-72.

Levitt, Theodore. 1983. The globalization of markets. Harvard Business Review, 61(3):92-102.

Li, Jiatao. 1995. Foreign entry and survival: Effects of strategic choices on performance in international markets. Strategic Management Journal, 16:333-51.

— \& Stephen E. Guisinger. 1991. Comparative business failures of foreign-controlled firms in the United States. Journal of International Business Studies, 22(2): 209-24.

Loree, David W. \& Stephen E. Guisinger. 1995. Policy and non-policy determinants of U.S. equity foreign direct investment. Journal of International Business Studies, 26(2):281-99.

Mitchell, Will, J. Myles Shaver \& Bernard Yeung. 1994. Foreign entrant survival and foreign market share: Canadian companies' experience in United States medical sector markets. Strategic Management Journal, 15:555-67.

Nordström, Kjell, A. 1991. The internationalization process of the firm. Searching for new patterns and explanations. Institute of International Business, Stockholm School of Economics, Stockholm.

Ohmae, Kenichi. 1985. Triad power: The coming shape of global competition. New York: The Free Press.

O'Reilly, Anthony J.F. 1991. The emergence of the global consumer. Directors \& Boards, 15(2):9-13.

Pennings, Johannes M., Harry G. Barkema \& Sytse W. Douma. 1994. Organizational learning and diversification. Academy of Management Journal, 37:608-40.

Read, Russell. 1993. Politics and policies of national economic growth. Unpublished doctoral dissertation, Stanford University.

Redding, S. Gordon. 1994. Comparative management theory: Jungle, zoo or fossil bed? Organization Studies, 15:323-59.

Roberts, Karlene H. \& Nakiye A. Boyacigiller. 1984. Cross-national organizational research: The grasp of the blind men. In B.M. Staw \& L.L. Cummings, editors, Research in organizational behavior. Greenwich, Conn.: JAI Press.

Ronen, Simcha \& Oded Shenkar. 1985. Clustering countries on attitudinal dimensions: A review and synthesis. Academy of Management Review, 10:435-54.

Rosten, Keith A. 1991. Soviet-U.S. joint ventures: Pioneers on a new frontier. California Management Review, 33:88-108.

Schein, Edgar H. 1985. Organizational culture and leadership. San Francisco: Jossey-Bass.

Schneider, Susan C. 1989. Strategy formulation: The impact of national culture. Organization Studies, 10:149-68. 
\& Arnoud De Meyer. 1991. Interpreting and responding to strategic issues: The impact of national culture. Strategic Management Journal, 12:307-20.

Shenkar, Oded \& Yoram Zeira. 1992. Role conflict and role ambiguity of chief executive officers in international joint ventures. Journal of International Business Studies, 23(1):55-75.

Soeters, Joseph \& Hein Schreuder. 1988. The interaction between national and organizational cultures in accounting firms. Accounting, Organizations and Society, 13:75-85.

Søndergaard, Mikael. 1994. Hofstede's consequences: A study of reviews, citations and replications. Organization Studies, 15:447-56.

Stopford, John M. \& Louis T. Wells, Jr. 1972. Managing the multinational enterprise. New York: Basic Books.

Tai, Lawrence S.T. 1988. Doing business in the people's republic of China: Some keys to success. Management International Review, 28:5-9.

Triandis, Harry C. 1982. Review of culture's consequences: International differences in workrelated values. Human Organization, 41:86-90.

Woodcock, Patrick \& J. Michael Geringer. 1991. An exploratory study of agency costs related to the control structure of multi-partner, international joint ventures. Academy of Management Best Paper Proceedings, 115-18. Yeh, Rhy-song \& John J. Lawrence. 1995. Individualism and Confucian dynamism: A note on Hofstede's cultural root to economic growth. Journal of International Business Studies, 26(3):655-69. 